\title{
Ocorrência de Vibrio parahaemolyticus em Mexilhões (Perna perna, Linnaeus, 1758) de Banco Natural do Litoral do Município de Palhoça, Santa Catarina, Brasil
}

\author{
Occurrence of Vibrio parahaemolyticus in Mussels (Perna perna, \\ Linnaeus, 1758) from a Natural Coastal Bed in the Municipality of \\ Palhoça, Santa Catarina, Brazil
}

\author{
Rita Maria B. Archer ${ }^{1}$ \\ Eliane Moretto ${ }^{2}$
}

ARCHER, M. R. B. E MORETTO, E. Occurrence of Vibrio parahaemolyticus in Mussels (Perna perna, Linnaeus, 1758) from a Natural Coastal Bed in the Municipality of Palhoça, Santa Catarina, Brazil. Cad. Saúde Públ., Rio de Faneiro, 10 (3): 379-386, Ful/Sep, 1994.

\begin{abstract}
A study was carried out on the occurrence of Vibrio parahaemolyticus in forty samples of mussels (Perna perna, Linnaeus, 1758) from a natural bed at Pinheira Beach, Municipality of Palhoça, Santa Catarina (Brazil), during a three-month period. The most probable number technique was used for isolation methodology with prior enrichment of samples in alkaline peptone water and subsequent planting on thiosulfate citrate bile salts sucrose agar. Vibrio parahaemolyticus was found in $52.5 \%$ of samples of mussels with a most probable number range of $<3$ to 93 organisms/g. Serotyping was performed on 61 isolates and our findings indicate that $36.1 \%$ of these isolates were serologically non-typable; $54.1 \%$ of isolates displayed only flagellate antigenic structures and $8.2 \%$ had both antigenic structures. None of the isolates were Kanagawa positive.
\end{abstract}

Key words: Vibrio parahaemolyticus; Mussels; Perna perna; Environmental Health

\section{INTRODUÇÃO}

No verão é intenso o consumo de frutos do mar, entre eles o mexilhão (Perna perna, Linnaeus, 1758). Bivalve de distribuição ampla e densidade populacional elevada no litoral catarinense, é também conhecido como marisco, marisco da pedra ou ostras de pobre sendo muito apreciado pela população local e pelo grande número de turistas que visitam as cidades balneárias, conforme Ferreira \& Magalhães (1992).

Os mexilhões são bivalves filtradores que se

${ }^{1}$ Laboratório Central de Saúde Pública de Santa Catarina. Avenida Rio Branco, 197, Caixa Postal 96, Florianópolis, SC, 88010-000, Brasil.

${ }^{2}$ Departamento de Ciência e Tecnologia de Alimentos da Universidade Federal de Santa Catarina. Rodovia SC 404, Florianópolis, SC, 88034-100, Brasil. alimentam de microrganismos captados pela corrente de água que é produzida pelo batimento dos cílios das brânquias. Não apresentam capacidade seletiva de filtração do seu alimento, sendo a ingestão de partículas selecionada apenas pelo tamanho. O fitoplâncton e os detritos (matéria orgânica particulada) são a principal fonte de alimento para o seu crescimento. Possuem uma taxa elevada de bombeamento de água, estimada entre 0,5 a quatro litros por hora dependendo do seu tamanho e das condições ambientais, de acordo com o Manual do Instituto Nacional de Estudos do Mar (Brasil, 1985). Seu habitat natural é a região do mesolitoral de costões rochosos, podendo estender-se até o infralitoral, numa profundidade de sete a dez metros, conforme Relatório da Fundação Instituto da Pesca do Estado do Rio de Janeiro \& Instituto de Pesca do Estado de São Paulo, (1989). 
Segundo Bigger apud Casas \& Hipólito (1988), as principais razões do perigo de se consumir moluscos bivalves decorrem da preferência desses animais por locais com aporte de águas doces, as quais podem estar contaminadas por dejetos domésticos ou industriais.

Numerosos casos de gastroenterite registrados no Japão, Estados Unidos, Canadá, Europa e México associados a ingestão de frutos do mar, têm como agente causal Vibrio parahaemolyticus uma bactéria estritamente marinha, segundo Barker Jr. (1974), Dadisman et al. (1973), Hoashi et al. (1990), Honda et al. (1987), Magalhães et al. (1991b).

As infecções por esse microrganismo são mais freqüentes nos meses de verão, período em que sua distribuição quantitativa no ambiente marinho é maior, salientam Kelly \& Stroh (1988), Liston \& Baross (1973).

O mecanismo de enteropatogenicidade do Vibrio parahaemolyticus permanece ainda uma incógnita. Durante os muitos estudos desse microrganismo como agente causador de gastroenterite, uma atividade hemolítica, independente do sorotipo, foi reconhecida: a capacidade de produzir $ß$-hemólise em agar Wagatsuma [meio básico acrescido de eritrócitos humanos e alta concentração de sal (7\%)]. O teste foi denominado Kanagawa e está estreitamente relacionado com a enteropatogenicidade, sendo adotado como parâmetro na identificação de cepas patogênicas e não-patogênicas. Essa atividade hemolítica é atribuída a uma hemolisina termoestável direta, considerada como principal fator de enteropatogenicidade, conforme Dadisman et al. (1973), Hoashi et al. (1990), Sarkar et al. (1987), Sochard \& Colwell (1977).

As cepas hemolíticas, Kanagawa positivas, são geralmente isoladas de material fecal de pacientes com gastroenterite, enquanto que as isoladas de amostras ambientais e de alimentos são, em cerca de $99 \%$ dos casos, Kanagawa negativas, mesmo se referidos alimentos estiverem envolvidos em casos de toxinfecção, o que faz dessa observação um fato interessante, porém ainda não explicado, segundo Barker (1974), Dadisman et al. (1973), Hofer \& Silva (1986), Kaysner et al. (1990), Rodrigues \& Hofer (1986), Tepedino (1982), Vanderzant \& Thompson (1973).

Estudos recentes demonstram que a hemo- lisina termoestável direta não é o único fator responsável pela enteropatogenicidade a qual pode ser atribuída a uma outra hemolisina, sugerindo que o fenômeno de Kanagawa não seria o indicador absoluto da enteropatogenicidade, de acordo com Hoashi et al. (1990), Honda et al. (1987), Miyamoto et al. (1969), Sarkar et al. (1987).

Outras infecções, como septicemias secundárias, otites e lesões da pele são causadas por Vibrio parahaemolyticus, segundo Elliot et al. (1991), Hoashi et al. (1990), Liston \& Baross (1973). Os casos de otites externas e lesões de pele estão associados ao contato com a água do mar. Referidas infecções ocorrem somente quando o microrganismo está presente em grande número no ambiente, ressaltam Kelly $\& \operatorname{Stroh}(1988)$.

Considerando-se a extensa faixa litorânea do país, discretas são as informações em nosso meio sobre a ocorrência de Vibrio parahaemolyticus no ambiente marinho, predominância de tipos sorológicos, bem como a sua incidência em casos de gastroenterites, conforme Barros \& Vianni (1980), Franca et al.(1980), Gelli et al.(1979), Hofer (1983), Leitão \& Arima (1975), Magalhães et al. (1991a, 1991b), Rodrigues \& Hofer (1986).

Optou-se pela região da Palhoça, Santa Catarina, por tratar-se de uma região de grande produção extrativa de mexilhões, aliado ao fato de ser um dos principais municípios que estão desenvolvendo a mitilicultura.

Com o presente estudo pretende-se fornecer dados quanto à ocorrência de Vibrio parahaemolyticus em mexilhões, os sorotipos predominantes e patogenicidade, fornecendo subsídios para futuros estudos de cunho ecológico, epidemiológico e microbiológico. Considerando que não dispomos de dados significativos, tanto a nível epidemiológico quanto sanitário, achamos de importância pesquisar a ocorrência de Vibrio parahaemolyticus em mexilhões devido ao risco potencial que esse microrganismo representa.

\section{MATERIAL E MÉTODOS}

\section{Amostragem}

As amostras de mexilhões foram extraídas manualmente do banco natural de bivalves de 
costão batido localizado na Ponta do Papagaio, Praia da Pinheira, município de Palhoça, pertencente a Grande Florianópolis, Santa Catarina. Este banco natural é parte de uma região de grande produção de mariscos localizada ao sul da Ilha de Santa Catarina.

O número de amostras analisadas foi de 40 , totalizadas em oito coletas de acordo com a International Comission on Microbiological Specifications for Foods (ICMSF, 1981).

\section{Coleta, Acondicionamento e Transporte}

As amostras foram coletadas a uma profundidade de 30 a $50 \mathrm{~cm}$ e acondicionadas em sacos plásticos dentro de caixas de isopor com gelo, mantendo uma temperatura entre 10 e $15 \mathrm{EC}$, sendo transportadas ao laboratório. No momento da coleta foram medidas a temperatura superficial e salinidade da água com o auxílio de termômetro com precisão de $0,5^{\circ} \mathrm{C}$ e refratômetro Bio Marine ABMNC, respectivamente.

O tempo decorrido entre a coleta das amostras e o início das análises não ultrapassou oito horas, conforme a American Public Health Association (APHA, 1984).

As amostras foram coletadas nos meses de verão (janeiro a março), período em que a incidência de Vibrio parahaemolyticus no ambiente marinho é maior, coincidindo com o período de consumo elevado de mexilhões.

\section{Procedimentos de Análise}

No laboratório, as conchas sofreram raspagem, lavagem e escovação sob água potável corrente tomando-se cuidado para não danificar as junturas das conchas. Os animais estavam vivos e com as conchas firmemente unidas. A seguir, foram colocadas em bandejas estéreis e deixadas secar à temperatura ambiente. Antes da abertura das conchas foram tomados cuidados quanto à higienização das mãos, realizada com água potável e sabão, seguida de rinsagem com álcool a 70\%, de acordo com a APHA (1984).

Depois de secas as conchas foram abertas com o auxílio de faca estéril, ponteaguda. Usando-se frasco estéril de boca larga, foram pesadas alíquotas de 50 gramas, constituídas de parte do tecido animal e parte do líquido intervalvar.

A seguir, procedeu-se a homogeneização com a adição de $450 \mathrm{ml}$ de salina fosfatada tamponada em desintegrador estéril, com velocidade de $8000 \mathrm{rpm}$, por 2 (dois) minutos, obtendo-se a diluição $10^{-1}$. A partir desta diluição foram preparadas diluições decimais subseqüentes até $10^{-4} \mathrm{em}$ salina fosfatada tamponada. A enumeração de Vibrio parahaemolyticus foi realizada pela técnica do Número Mais Provável (NMP), com enriquecimento em água alcalina peptonada, inoculando-se de cada diluição, alíquotas de $1 \mathrm{ml}$ em quatro séries de diluições triplicadas de tubos $(18 \times 180 \mathrm{~mm})$ contendo $10 \mathrm{ml}$ de água alcalina peptonada, de acordo com Elliot et al. (1991).

Após o período de incubação a $35-37^{\circ} \mathrm{C}$ por 16-18 horas, o material de cada tubo foi semeado, pelo método de estriação, em Thiosulfate Citrate Bile Salts Sucrose agar (TCBS, MERCK 10263) e incubando-se, então, a $35-37^{\circ} \mathrm{C}$ por 18-24 horas, segundo Elliot et al. (1991).

A seguir, três a cinco colônias típicas, verdeazuladas com 2 a $3 \mathrm{~mm}$ de diâmetro, foram inoculadas em ágar Kligler (MERCK 3913) e em ágar nutriente, sendo incubadas a $35-37^{\circ} \mathrm{C}$ por 24 horas, segundo Elliot et al. (1991).

Após o período de incubação em ágar Kligler e interpretados os resultados obtidos, as cepas presuntivas de Vibrio parahaemolyticus, a partir do ágar nutriente, foram submetidas a testes complementares morfológicos e bioquímicos, de acordo com Elliot et al. (1991).

Todos os meios para testes de reações bioquímicas foram acrescidos de $2 \%$ de $\mathrm{NaCl}$, segundo Elliot et al. (1991).

Para acompanhamento dos testes bioquímicos de identificação utilizou-se uma cultura controle cedida pelo Instituto Adolfo Lutz(IAL), São Paulo.

As culturas com comportamento da espécie, representativas das diferentes amostras, foram enviadas ao Departamento de Bacteriologia da Fundação Instituto Oswaldo Cruz (Fiocruz, Rio de Janeiro) para caracterização sorológica e realização do teste de Kanagawa, conforme Elliot et al. (1991).

Após a identificação bioquímica e sorológica, 
foi aplicada a tabela do Número Mais Provável (NMP), de acordo com a APHA (1984), para a determinação da expressão numérica.

\section{RESULTADOS E DISCUSSÃO}

Os resultados obtidos no presente trabalho estão apresentados nas Tabelas 1 a 3 .

Esses resultados indicam um índice de contaminação por Vibrio parahaemolyticus de 52,5\% das amostras de mexilhões, com valores entre $<3$ e $93 \mathrm{NMP} / \mathrm{g}$, como podemos observar nas Tabelas 1 e 2 .
Tal constatação confirma observações de outros autores: Gelli et al. (1975) obtiveram valores mais expressivos, $84,28 \%$ de positividade em amostras de ostras do litoral paulista. Gelli et al. (1979) em outra ocasião, também analisando ostras, constataram contaminação em $100 \%$ das amostras, com valores entre 9,1 e 3,6 x $10^{6} \mathrm{NMP} / \mathrm{g}$. Kaysner et al. (1990) constataram contaminação em $100 \%$ das amostras com valores entre 0,4 e $15 \mathrm{NMP} / \mathrm{g}$ em ostras de Grays Harbor nos Estados Unidos e Tepedino (1982) registrou 33\% de amostras contaminadas, com valores entre 3,6 e $23 \mathrm{NMP} / \mathrm{g}$ de ostras de Long Island, também nos EUA.

TABELA 1. Ocorrência de Vibrio parahaemolyticus em Amostras de Mexilhões Provenientes de Banco Natural do Litoral de Palhoça, Santa Catarina, Janeiro a Março de 1993

\begin{tabular}{|c|c|c|c|}
\hline \multirow{2}{*}{$\begin{array}{l}\mathrm{N}^{\mathrm{o}} \mathrm{de} \\
\text { Coletas }\end{array}$} & \multirow{2}{*}{$\begin{array}{c}\mathrm{N}^{\circ} \text { de Amostras } \\
\text { Analisadas }\end{array}$} & \multicolumn{2}{|c|}{ Amostras Positivas } \\
\hline & & $\mathrm{N}^{\mathrm{o}}$ & $\%$ \\
\hline 8 & 40 & 21 & 52,5 \\
\hline
\end{tabular}

TABELA 2. Distribuição das Estimativas de Vibrio parahaemolyticus pelo Número Mais Provável (NMP/g) em Amostras de Mexilhões Provenientes de Banco Natural do Litoral de Palhoça, Santa Catarina, Janeiro a Março de 1993

\begin{tabular}{|c|c|c|c|c|c|c|c|c|}
\hline \multirow[b]{2}{*}{ Coletas } & \multirow{2}{*}{$\begin{array}{c}\text { Data } \\
\text { da } \\
\text { Coleta }\end{array}$} & \multicolumn{5}{|c|}{$\begin{array}{c}\mathrm{NMP} / \mathrm{g} \text { de } \\
\text { Vibrio parahaemolyticus } \\
\text { nas Amostras }\end{array}$} & \multirow{2}{*}{$\begin{array}{c}\begin{array}{c}\text { Salinidade } \\
\text { da } \\
\text { Água }\end{array} \\
(\%)\end{array}$} & \multirow{2}{*}{$\begin{array}{c}\begin{array}{c}\text { Temperatura } \\
\text { da } \\
\text { Água }\end{array} \\
(\mathrm{C})\end{array}$} \\
\hline & & 01 & 02 & 03 & 04 & 05 & & \\
\hline 01 & $19 / 01$ & 3 & $<3$ & 3 & 3 & 4 & 35,0 & 23,0 \\
\hline 02 & $26 / 01$ & $<3$ & $<3$ & $<3$ & $<3$ & $<3$ & 36,0 & 24,0 \\
\hline 03 & $02 / 02$ & $<3$ & $<3$ & $<3$ & $<3$ & $<3$ & 35,0 & 26,0 \\
\hline 04 & $08 / 02$ & 23 & $<3$ & 15 & $<3$ & $<3$ & 36,0 & 26,5 \\
\hline 05 & $16 / 02$ & 9 & 11 & $<3$ & 7 & $<3$ & 36,5 & 28,5 \\
\hline 06 & $09 / 03$ & 43 & 20 & 7 & 93 & 9 & 35,5 & 26,5 \\
\hline 07 & $16 / 03$ & $<3$ & $<3$ & 3 & 7 & 7 & 36,0 & 23,0 \\
\hline 08 & $22 / 03$ & 9 & 9 & 11 & $<3$ & 3 & 35,0 & 26,0 \\
\hline
\end{tabular}

Com relação às condições ambientais de temperatura e salinidade da água durante o período de coleta das amostras, caracterizaramse por médias de $25,4^{\circ} \mathrm{C}$ e $35,6 \%$, para temperatura e salinidade respectivamente.
A análise sorológica das culturas típicas por nós isoladas, evidenciou um considerável número, $36,1 \%$, de culturas nas quais não foi possível caracterizar as estruturas antigênicas O e K. Das demais culturas, $54,1 \%$ permitiram a 
identificação somente do antígeno $\mathrm{K}$ e apenas $8,2 \%$ tiveram ambas as estruturas caracterizadas, como pode ser observado na Tabela 3.

Esse fato também foi observado por outros autores, onde nem sempre foi possível a definição das estruturas $\mathrm{O}$ e $\mathrm{K}$ das culturas de origem ambiental. A porcentagem de culturas não tipificáveis pode ser expressiva, chegando a ultrapassar 50\%. Fishbein et al. (1970) verificaram $61 \%$ de culturas não-tipificáveis, Vanderzant \& Thompson (1973) relataram 79\% e Leitão \& Arima (1975), relataram $40 \%$.

Observamos que a maioria das culturas, $24 \%$, apresentou o antígeno $\mathrm{K}$ identificado, com predominância do K30. O sorotipo O5:K30, presente em $5 \%$ das culturas testadas, também foi encontrado por outros autores brasileiros testando culturas de origem ambiental: Hofer \& Silva (1986) relataram 1,4\%, Leitão \& Arima (1975), 4\%, e Magalhães et al. (1991a), 4,16\%. Gelli et al. (1975) relataram uma incidência de 2,5\% do sorotipo O3: K30.

Como a maioria das culturas não tiveram ambos antígenos determinados e outras apenas identificado a estrutura $\mathrm{K}$, acreditamos que possam pertencer a vários sorotipos.

TABELA 3. Identificação Sorológica de Culturas de Vibrio parahaemolyticus Isoladas de Amostras de Mexilhões Coletadas de Banco Natural do Litoral de Palhoça, Santa Catarina, Janeiro a Março de 1993

\begin{tabular}{lcc}
\hline \hline \multirow{2}{*}{ Sorovars } & \multicolumn{2}{c}{ Ocorrência } \\
\cline { 2 - 3 } & Número & Porcentagem \\
\hline OND: KND & 22 & 36,1 \\
OND: K30 & 11 & 18,0 \\
OND: K17 & 08 & 13,3 \\
OND: K39 & 07 & 11,5 \\
OND: K22 & 04 & 6,5 \\
O5: K30 & 03 & 5,0 \\
O1: K30 & 01 & 1,6 \\
O3: K17 & 01 & 1,6 \\
O5: KND & 01 & 1,6 \\
OND: K13 & 01 & 1,6 \\
OND: K34 & 01 & 1,6 \\
OND: K11 & 01 & 1,6 \\
\hline Total & 61 & 100,0 \\
\hline \hline
\end{tabular}

ND: não determinado

Esse elevado número de culturas não-tipificáveis com os 71 anti-soros disponíveis mostra a extraordinária diversidade de sorotipos ocorrentes em nosso meio, salientando o caráter ubiqüitário desse microrganismo e sugerindo a necessidade de novos estudos a respeito.

A caracterização sorológica, secundária na identificação de Vibrio parahaemolyticus, é de interesse quando aplicada a áreas não-endêmicas, logrando caracterizar os sorotipos presentes.
Hofer \& Silva (1986) sugerem que inúmeros fatores podem exercer influência sobre a heterogeneidade dos sorotipos, referindo como hipóteses, o local e espécies analisadas, fatores químicos, físicos e biológicos presentes nos ecossistemas estudados, assim como a metodologia empregada.

Todas as culturas testadas apresentaram-se dentro das características bioquímicas da espécie e nenhuma apresentou o fenômeno de Kanagawa. Tal constatação está em concordân- 
cia com publicações de outros autores: Barker Jr. (1974), Hoashi et al. (1990), Kaysner et al. (1990), Miyamoto et al. (1969) demostraram que culturas isoladas do ambiente marinho apresentaram pouca ou nenhuma atividade hemolítica $(0,5-1 \%)$, em oposição às culturas Kanagawa positivas freqüentemente isoladas de casos clínicos, segundo Barker (1974), Hoashi et al. (1990), Magalhães et al. (1991a). Porém, nos confrontamos com publicações que relatam incidência mais expressiva de culturas Kanagawa positivas isoladas do ambiente. Barros \& Vianni (1980) registraram uma incidência de 1,43\% de culturas isoladas de águas da Baía da Guanabara, enquanto Vanderzant \& Thompson (1973) afirmaram que esse índice foi de $20 \%$ em culturas isoladas de ostras, sedimentos e águas da Baía de Galveston.

\section{CONCLUSÃO}

Apesar do pequeno número de Vibrio parahaemolyticus detectado nas amostras de mexilhões e de que as cepas isoladas não são hemolíticas, não está excluída a possibilidade de uma toxinfecção humana. Como já mencionado, a associação entre hemolisina termoestável direta e patogenicidade é questionada, já que casos de infecções gastrointestinais são atribuídos a cepas Kanagawa negativas.

\section{AGRADECIMENTOS}

Aos professores Aimê Raquel M. Magalhães e Jaime Fernando Ferreira e à equipe técnica do Laboratório de Mexilhões do Departamento de Aqüicultura da Universidade Federal de Santa Catarina, pelo valioso auxílio na coleta das amostras e esclarecimentos prestados.

À Dra. Dália dos Prazeres Rodrigues da Fundação Oswaldo Cruz, pela realização do teste de Kanagawa e identificação sorológica.

\section{RESUMO}

ARCHER, R. M. B. \& MORETTO, E. Ocorrência de Vibrio parahaemolyticus em Mexilhões (Perna perna, Linnaeus, 1758) de Banco Natural do Litoral do Município de Palhoça, Santa Catarina, Brasil. Cad. Saúde Públ., Rio de Janeiro, 10 (3): 379-386, jul/set, 1994.

Foi estudada a ocorrência de Vibrio parahaemolyticus em quarenta amostras de mexilhões (Perna perna, Linnaeus, 1758) procedentes de banco natural da praia da Pinheira, município de Palhoça, Santa catarina, durante um período de três meses. $\mathrm{Na}$ metodologia de isolamento foi utilizada a técnica do Número Mais Provável (NMP) com enriquecimento em água alcalina peptonada e subseqüente plaqueamento em ágar TCBS (thiosulfate citrate bile salts sucrose). Em $52,5 \%$ das amostras de mexilhões foi constatada a presença de Vibrio parahaemolyticus, com níveis de contaminação entre <3 e 93 NMP/g. $\mathrm{Na}$ caracterização sorológica de 61 culturas, $36,1 \%$ não permitiram a identificação das estruturas antigênicas $\mathrm{O}$ e $\mathrm{K} ; 54,1 \%$ somente da estrutura $\mathrm{K}$ e apenas $8,2 \%$ tiveram ambas as estruturas definidas. Nenhuma dessas culturas apresentou positividade para o teste de Kanagawa.

Palavras-Chave: Vibrio parahaemolyticus; Mexilhões; Perna perna; Saúde Ambiental

\section{REFERÊNCIAS BIBLIOGRÁFICAS}

APHA (American Public Health Association), 1984. Compendium of Methods for the Microbiological Examination of Foods. $2^{\text {nd }}$ ed., Washington, DC: Marvin Speck.

BARKERJR., W. H., 1974. Vibrio parahaemolyticus outbreaks in the United States. The Lancet, 1: 551-554.

BARROS, G. C. \& VIANNI, M. C. E., 1980. Vibrio parahaemolyticus: isolamento e identificação em águas da Baía de Guanabara. Revista Latinoamericana de Microbiologia, 22: 163-169. 
BRASIL (Ministério da Marinha, Instituto Nacional de Estudos do Mar), 1985. Manual de Maricultura. Rio de Janeiro: IpqM.

CASAS, M. G. \& HIPÓLITO, M., 1988. Análise bacteriológica qualitativa em moluscos bivalves e sua importância na saúde pública. Anais do VI Simpósio Latinoamericano de Agricultura, V Simpósio Brasileiro de Aqüicultura, Florianópolis: ABRAq. (Mimeo.)

DADISMAN, T. A.; NELSON, R.; MOLENDA, J. R. \& GARBER, H. J., 1973. Vibrio parahaemolyticus gastroenteritis in Maryland: clinical and epidemiologic aspects. Fournal of Milk and Food Technology, 36: 111-112.

ELLIOT,E. L.; KAYSNER, C. A. \& TAMPLIN, M. L., 1991. Vibrio cholera, Vibrio parahaemolyticus, Vibrio vulnificus and other Vibrio spp. In: Bacteriological Analytical Manual (Association of Official Analytical Chemists, ed.), Washington, D.C.: Food and Drug Administration.

FERREIRA, J. F. \& MAGALHÃES, A. R. M., 1992. Cultivo de mexilhões em Santa Catarina. Panorama da Aqüicultura, 14: 10-11.

FIPERJ (Fundação Instituto da Pesca do Estado do Rio de Janeiro) \& IP (Instituto de Pesca do Estado de São Paulo), 1989. Apoio ao Desenvolvimento do Cultivo de Moluscos Bivalves no Brasil. Rio de Janeiro: Fiperj/IP. (Mimeo.)

FISHBEIN, M.; MEHLMAN, I. J. \& PITCHER, J., 1970. Isolation of Vibrio parahaemolyticus from the processed meat of Chesapeak Bay blue crabs. Applied Microbiology, 20: 176-178.

FRANCA, S. M. C.; GIBBS, D. L.; SAMUELS, P. \& JOHNSON, W.D., 1980. Vibrio parahaemoliticus in Brazilian coastal waters. Fournal of the American Medical Association, 244: 587-588.

GELLI, D. S.; TACHIBANA, T. \& SAKUMA, H., 1979. Ocorrência de Vibrio parahaemolyticus, Escherichia coli e de bactérias mesófilas em ostras. Revista do Instituto Adolfo Lutz, 39: 61-66.

GELLI, D. S.; TACHIBANA, T. \& SILVA, T. M. P., 1975. Ocorrência de Vibrio parahaemolyticus em ostras e outros produtos marinhos no litoral de São Paulo, Brasil. Revisão e considerações sobre o risco potencial para a saúde pública. Revista do Instituto Adolfo Lutz, 35: 9-16.
HOASHI, K.; OGATA, K.; TANIGUCHI, H.; YAMASHITA, H.; TSUJI, K.; MIZUGUCHI, Y. \& OHTOMO, N., 1990. Pathogenesis of Vibrio parahaemolyticus: intraperitoneal and orogastric challenge experiments in mice. Microbiology and Immunology fournal, 34: 355366.

HOFER, E., 1983. Primeiro isolamento e identificação de Vibrio parahaemolyticus no Brasil de infecção gastrointestinal. Revista de Microbiologia, 14: 174-175.

HOFER, E. \& SILVA, C. H. D., 1986. Caracterização sorológica de amostras de Vibrio parahae molyticus isoladas de peixes capturados no litoral brasileiro. Revista de Microbiologia, 17: 327-331.

HONDA, S. I.; GOTO, I.; MINEMATSU, I.; IKEDA, N. \& ASANO, N., 1987. Grastroenteritis due to Kanagawa negative Vibrio parahaemolyticus. The Lancet, 8528: 331-332.

ICMSF (International Comission on Microbiological Specifications for Foods), 1981. Microorganismos de los Alimentos. Métodos de Muestre para Análisis Microbiológicos: Principios y Aplicaciones Específicas. Vol. 2, Zaragoza: Acribia.

KAYSNER, C. A.; ABEYTA, C.; STOTT, R. F.; KRANE, M. H. \& WEKELL, M. M., 1990.

Enumeration of Vibrio species, including Vibrio cholera, from samples of an oyster growing area, Grays Harbor, Washington. Fournal of Food Protection, 53: 300-301.

KELLY,M. T. \& STROH, E. M. D., 1988. Temporal relationship of Vibrio parahaemolyticus in patients and the environment. Fournal of Clinical Microbiology, 26: 1754-1756.

LEITÃO, M. F. F. \& ARIMA, H. K., 1975. Vibrio parahaemolyticus no ambiente marinho do Estado de São Paulo. Coletânea do Instituto de Tecnologia de Alimentos, 6: 149-166.

LISTON, J. \& BAROSS, J., 1973. Distribution of Vibrio parahaemolyticus in the natural environment. Fournal of Milk and Food Technology, 36: 113-117.

MAGALHÃES, M.; MAGALHÃES, V.; ANTAS, M. G. \& TATENO, S., 1991a. Caracterização bacteriológica e sorológica de linhagens de Vibrio parahaemolyticus isoladas de humanos e de ostras no Recife, Brasil. Revista de Microbiologia, 22: 83-88. 
MAGALHÃES, V.; LIMA, R. A.; TATENO, S. \& MAGALHÂES, M., 1991b. Gastroenterites humanas associadas a Vibrio parahaemolyticus no Recife, Brasil. Revista do Instituto de Medicina Tropical, 33: 64-68.

MIYAMOTO, Y.; KATO, T.; OBARA, Y.; AKIYAMA, S.; TAKIZAWA, K. \& YAMAI, S., 1969. In vitro hemolytic characteristic of Vibrio parahaemolyticus: its close correlation with human pathogenicity. Fournal of Bacteriology, 100: 1147-1149.

RODRIGUES, D. P. \& HOFER, E., 1986. Vibrio species from the water-oyster ecosystem of Sepetiba Bay in Rio de Janeiro State, Brazil. Revista de Microbiologia, 17: 332-338.

SARKAR, B. L.; KUMAR, R.; DE, S. P. \& PAL, S. C., 1987. Hemolitic acitivity of and lethal toxin production by environmental strains of Vibrio parahaemolyticus. Applied and Environmental Microbiology, 35: 2696-2698.
SOCHARD, M. R. \& COLWELL, R. R., 1977. Toxin isolation from Kanagawa phenomenon negative strain of Vibrio parahaemolyticus. Microbiology and Immunology, 21: 243-254.

TEPEDINO, A. A., 1982. Vibrio parahaemolyticus in Long Island oysters. Fournal of Food Protection, $45: 150-151$.

VANDERZANT, C. \& THOMPSON, C. A., 1973. Microbial flora and level of Vibrio parahaemolyticus of oysters (Crassostrea virginica), water, and sediment from Galveston Bay. Journal of Milk and Food Technology, 36: 447-452. 